\title{
A guitarra e o martelo: uma crítica nietzschiana à religião enquanto agenciamento moral no filme Tommy
}

\author{
The guitar and the hammer: a nietzschean critique on religion as a moral \\ agency in the movie Tommy

\section{La guitarra y el martillo: una crítica nietzscheana de la religión como agencia} \\ moral em la película Tommy \\ Roberto Corrêa Scienzal \\ Silvio Demétrio ${ }^{2}$
}

\begin{abstract}
Resumo
Pretende-se desenvolver uma análise fílmica, sob as diretrizes de Jacques Aumont e Michel Marie, de Tommy - filme musical, de 1975, dirigido por Ken Russell, baseado no álbum/ópera rock homônimo da banda britânica The Who - com o intuito de desvelar uma crítica à religião enquanto agenciamento moral. Para estabelecer as bases filosóficas desse problema moral, recorre-se, respectivamente, ao filósofo alemão Friedrich Wilhelm Nietzsche e aos filósofos franceses Gilles Deleuze e Michel Foucault. Desvela-se, a partir da análise fílmica de Tommy, a seguinte crítica: a religião, por meio de seus dogmas; da alienação; da castração dos sentidos e instintos; do conforto no ressentimento; cria uma estrutura autista em quem a experiencia, impedindo o exercício da vontade de potência e o Amor fati.
\end{abstract}

Palavras-chave: Religião. Moral. Nietzsche. Tommy. The Who.

\begin{abstract}
We intend to develop a film analysis, under the light of Jacques Aumont and Michel Marie, of Tommy - musical film, released in 1975, directed by Ken Russell, based on the album/rock opera of the same name of the British band The Who - to highlight a critique on religion as a moral agency. We use the philosophy of Friedrich Nietzsche, Gilles Deleuze and Michel Foucault to establish the basis of this moral problem. The film analysis unveils: religion, through its dogmas; alienation; the castration of the senses and instincts; the comfort in resentment; creates an autistic structure in who experiences it, eliminating the will to power and the Amor fati.
\end{abstract}

Keywords: Religion. Moral. Nietzsche. Tommy.The Who.

\begin{tabular}{|c|c|}
\hline & Icesse est \\
\hline \multirow{2}{*}{ 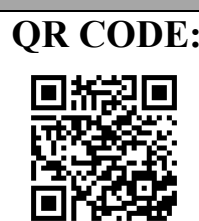 } & $\begin{array}{l}\text { Website: } \\
\text { http://www.revistas.ufg.br/index.php/ci }\end{array}$ \\
\hline & $\begin{array}{l}\text { DOI: } \\
\text { http://dx.doi.org/10.5216/c\&i.v19i1.369 } \\
87\end{array}$ \\
\hline
\end{tabular}

\section{Resumen}

Tenemos la intención de elaborar un análisis fílmico, en la luz de Jacques Aumont y Michel Marie, de Tommy - película musical, de 1975, dirigida por Ken Russell, basada en el álbum/ópera rock de mismo nombre de la banda británica The Who - con la intención

\footnotetext{
${ }^{1}$ Mestrando em Comunicação na Universidade Estadual de Londrina (UEL), Graduado em Comunicação Social - Publicidade e Propaganda pela Universidade Estadual do Centro-Oeste (UNICENTRO). Brasil, Paraná, Londrina. E-mail: robcorreasc@gmail.com

${ }^{2}$ Doutorado em Epistemologia da Pesquisa Em Comunicação pela Universidade de São Paulo (USP), mestre em Ciências da Comunicação pela Universidade de São Paulo (USP), graduado em Comunicação Social Jornalismo pela Universidade Estadual de Londrina (UEL). Professor adjunto da Universidade Estadual de Londrina (UEL) na graduação em Comunicação Social - Jornalismo e no programa de mestrado em Comunicação Visual. Brasil, Paraná, Londrina. E-mail: silviodemetrio@uel.br
}

Comun. \& Inf., Goiânia, GO, v. 19, n. 01, p. 105-122, jan./jun. 2016 
de develar una crítica de la religión como agencia moral. Se utiliza la filosofía de Friedrich Nietzsche, Gilles Deleuze y Michel Foucault para establecer las bases de este problema moral. El análisis filmico de Tommy devela la siguiente crítica: la religión, a través de sus dogmas; de la alienación; de la castración de los sentidos y de los instintos; del consuelo en el resentimiento; crea una estructura autista en los que la experiencian, lo que impide el ejercicio de la voluntad de poder y el Amor fati.

Palavras clave: Religión. Moral. Nietzsche. Tommy. The Who.

\section{INTRODUÇÃO}

guitarra e o martelo. Instrumentos de desconstrução de paradigmas.
Velhos hábitos são abolidos e superados; novos devires alçados. É assim
o Rock $N^{\prime}$ Roll e a Filosofia par excellence.

E assim poderia ser a comunicação, pois esta apresenta características libertárias, por outro lado, características também conservadoras; "furta-se a qualquer determinação, como se fosse a peste. Aspira a ser ao mesmo tempo uma coisa, o seu contrário e tudo quanto está no meio, entre os dois opostos" (PERNIOLA, 2005, p. 14). Uma posição, evidentemente poderosa, e talvez este seja o porquê de sua consciente neutralidade.

Cabe ao pesquisador da comunicação assumir um lado e não se posicionar na confortável neutralidade ética que seu campo manifesta. Ser extra-modelo ou moralista; nômade ou sedentário; libertário ou conservador. A imparcialidade sem crítica da comunicação, inimiga dos contrastes, que dissolve todos os conteúdos e que toma todos os partidos, não deve alcançar o pensamento científico.

Este trabalho assume a responsabilidade de estar à deriva; à margem da moral e de seus respectivos agenciamentos. À vista disso, pretende-se desenvolver uma análise fílmica de Tommy - filme musical, de 1975, dirigido por Ken Russell, baseado no álbum/ópera rock homônimo, de 1969, da banda britânica The Who - com o intuito de desvelar uma crítica à religião enquanto agenciamento moral.

Uma melhor compreensão dos agenciamentos e discursos morais pode oferecer novas perspectivas para o entendimento das práticas e comportamentos sociais, um dos objetivos mais amplos do campo da comunicação. Para estabelecer as bases filosóficas desse problema moral, recorre-se, respectivamente, ao filósofo alemão Friedrich Wilhelm Nietzsche e aos filósofos franceses Gilles Deleuze e Michel Foucault.

Num primeiro momento, introduz-se ao The Who, banda criadora da ópera rock em que o filme analisado se baseia, em seguida, apresenta-se a metodologia utilizada para a análise fílmica e os pressupostos teóricos para a crítica à religião empreendida pelo discurso do filme. Prontamente, desenvolve-se uma breve descrição técnica e narrativa do filme para que, então, se possa adentrar a análise fílmica. 
Desvela-se, a partir da análise fílmica de Tommy, a seguinte crítica: a religião, por meio de seus dogmas; da alienação; da castração dos sentidos e instintos; do conforto no ressentimento; cria uma estrutura autista em quem a experiencia, impedindo o exercício da vontade de potência e o Amor fati.

\section{THE WHO}

A banda britânica de rock The Who começou a ser formada em 1961, ainda sob o nome de The Detours e tocando um estilo bem diferente daquele que os tornaria conhecidos o Skiffle ${ }^{3}$ Em 1964, já com a formação que seria consagrada clássica (Townshend, Daltrey, Entwistle, Moon), mudam seu nome para The Who e em 1965 lançam seu primeiro Long Play (LP), intitulado My Generation, que chega ao quinto lugar na parada musical do Reino Unido.

O The Who se tornou uma das bandas mais importantes e influentes de toda a história do Rock, com milhões de discos vendidos, shows por todo o mundo, prêmios, honrarias e uma legião de fãs ao redor do planeta. A banda foi introduzida ao Rock $N^{\prime}$ Roll Hall of Fame ${ }^{4}$ em 1990; possui sete álbuns incluídos no rol dos 500 melhores álbuns da história da revista Rolling Stone; o portal About.com, afiliado ao jornal New York Times, deu a ela o $3^{\circ}$ lugar no Top 50 Classic Rock bands; é dona da nona posição entre os melhores artistas de todos os tempos do canal de televisão $V H 1$.

O grupo já tocou em festivais importantes como Monterey Pop Festival (1967), Woodstock Music \& Art Fair (1969), Isle of Wight Festival (1970) e em grandes eventos como o Intervalo do Super Bowl XLIV (2010). É conhecido por hits como My Generation, Pimball Wizard, Won't get Fooled Again, Baba O' Riley entre outros.

O The Who também é dono da primeira obra explicitamente considerada como ópera rock $^{5}$ - denominada Tommy, de1969, quarto álbum de estúdio da banda. Na época de lançamento, ficou em quarto lugar na parada musical americana (permanecendo na parada por 47 semanas) e em segundo lugar no Reino Unido. A grande maioria das canções foi composta por Pete Townshend. O filme Tommy, de 1975, objeto de análise deste artigo, foi baseado no referido álbum da banda.

\footnotetext{
${ }^{3}$ É um tipo de música folk, com influências de Blues, Bluegrass e Country. Muito popular entre os jovens britânicos na década de 50. Uma característica dos grupos de Skiffle é a utilização de instrumentos improvisados, como garrafas, caixas de chá e tábuas de lavar roupa.

${ }^{4}$ Museu e instituição localizados em Cleveland, Ohio, EUA. Dedica-se a registrar a história dos maiores nomes do Rock e do Pop.

${ }^{5}$ Há especulações de que "The Story of Simon Simopath" (1967) da banda Nirvana e "S. F. Sorrow" (1968) da banda Pretty Things são as primeiras óperas rock.
} 


\section{ANÁLISE FÍLMICA}

Para explicitar os discursos audiovisuais do filmeTommy, utiliza-se a metodologia de análise fílmica. Propõe-se uma análise temática de Tommy com o intuito de desvelar uma crítica à religião enquanto agenciamento moral.

A análise deve levar em conta, geralmente, três tipos de instrumentos para que se possa analisar um filme: a) instrumentos descritivos, que têm a função de descrever unidades narrativas, características da imagem e do som; b) instrumentos citacionais, que se limitam ao texto ou "letra" do filme; c) instrumentos documentais, que não estão ligados diretamente ao filme - informações provenientes de fontes exteriores a ele (AUMONT; MARIE, 2013). Pergunta-se acerca do filme analisado: de que fala? (seus temas); o que conta? (sua narrativa); o que diz? (seu discurso, sua tese) (AUMONT; MARIE, 2013). Tais questionamentos devem ser respondidos a partir da análise fílmica para que se possa tomar o filme como objeto de discussão.

É importante destacar que, para o analista fílmico, "o conteúdo de um filme nunca é um dado imediato, mas deve, em qualquer caso, construir-se" (AUMONT; MARIE, 2013, p. 120), portanto, a análise fílmica nunca desvela um sentido único, mas novas discussões, percepções e perspectivas acerca do filme analisado. Outro item relevante para a análise fílmica é entender que o filme não deve ser apenas um meio, mas também um fim. O ponto de partida, mas também de chegada da análise (AUMONT; MARIE, 2013), portanto, este se fecha (completa-se) em si mesmo.

\section{O PROBLEMA MORAL}

Para desvelar a crítica à religião empreendida por Tommy, é preciso entender o problema moral e seus pressupostos teóricos. O filósofo alemão Friedrich Nietzsche desenvolveu incisivas críticas ao referido problema.

O problema moral nietzschiano pode ser introduzido a partir de alguns questionamentos: qual a validade dos valores morais que são tomados como supremos e absolutos? Eles, até hoje, estimularam a construção da ponte para o Super-homem ou inibiram a vontade de potência do ser humano? É necessário questionar e criticar tais valores para que se possa chegar à raiz de suas criações e entender se são valores que afirmam a vida ou o ressentimento (NIETZSCHE, 2008a).

Para Nietzsche (2012a, p. 122), "bem e mal imorredouros não existem”, são apenas percepções fundadas em - institucionalizadas por - uma moral vigente. Logo, nenhum 
fenômeno é moral por si próprio, mas pode ser interpretado moralmente. "O juízo moral tem em comum com o juízo religioso o crer em realidades que não existem. A moral é tão somente uma interpretação de certos fenômenos, porém uma falsa interpretação". (NIETZSCHE, 2001, p. 43). Um bom exemplo é a divergência de interpretações que as religiões têm do ato sexual: "o cristianismo o teria associado ao mal, ao pecado, à queda, à morte, ao passo que a Antiguidade o teria dotado de significações positivas" (FOUCAUT, 1998, p. 17). A religião, logo, não passa de uma interpretação da vida e do mundo; de moral antinatural, ensinada, inimiga e condenadora dos instintos vitais.

Recorre-se a Deleuze para introduzir o conceito de agenciamento. Para o filósofo, um agenciamento é um co-funcioamento de elementos heterogêneos. Uma relação de simultaneidade e simpatia entre diferentes coisas.

O que é um agenciamento? Um agenciamento é uma multiplicidade que comporta muitos termos heterogêneos e que estabelece ligações, relações entre eles, a partir das idades, de sexos e de reinos - de diferentes naturezas. A única unidade do agenciamento é o co-funcionamento: uma simbiose, uma simpatia $^{6}$ (DELEUZE; PARNET, 1980, p. 79).

A religião é também uma multiplicidade constituída de elementos diversos que estabelecem ligações. Logo, um agenciamento. No entanto, promove discursos normatizadores, opressores e repressores; financia fundamentalismos e preconceitos; assume posições de poder. Portanto, um agenciamento moral. A moral funciona como um agenciamento maior de outros agenciamentos como, além da religião, podem ser também o Estado, o Capital e outros. A instituição e manutenção da moral cabem a esses agenciamentos que produzem discursos normatizadores.

O agenciamento Religião não só constrói, mas dogmatiza modelos morais por meio do discurso religioso. "Essa moral diz teimosa e implacavelmente "eu sou a própria moral, e não há moral fora de mim!" (NIETZSCHE, 2011, p. 116). Quem não adota o modelo moral preterido - quem não obedece a seus dogmas - será punido (pagará por seus pecados). Tais dogmas, em sua grande maioria, são fundados em um regime de compensação. O sofrimento e a humilhação que se tem são necessários para que seja possível o caminho para a iluminação posterior. É a ideia de que se sofres hoje, serás recompensado amanhã. Para Nietzsche,

\footnotetext{
"“Qué es un agenciamiento? Un agenciamiento es una multiplicidad que comporta muchos términos heterogéneos, y que establece uniones, relaciones entre ellos, a través de edades, de sexos y de reinos - a través de diferentes naturalezas. La única unidad del agenciamiento es de co-funcionamiento: una simbiosis, una simpatia”.
} 
a religião proporciona um conformismo inestimável em face da sua situação e existência, uma múltipla paz do coração, um enobrecimento da sua obediência, além de uma felicidade e uma dor mais iguais às dos seus, e uma espécie de transfiguração e de embelezamento, uma espécie de justificação de toda a vida quotidiana, de toda a baixeza, de toda a pobreza quase animal da sua alma (NIETZSCHE, 2011, p. 85).

O filósofo não só repudia dogmas e modelos morais ${ }^{7}$, mas evidencia que a religião por enaltecer valores que oprimem os instintos; deformam os sentidos; condenam o prazer e negam o desejo e a vida em prol de uma recompensa futura - é um obstáculo ao homem de exercer seu poder criador, sua vontade de potência. "A vontade de potência não é um ser, não é um devir, mas um pathos, - ela é o fato elementar de onde resulta um devir e uma ação..." (NIETZSCHE, 2012b, p. 106). Sem vontade de potência, o homem passa a não agir, apenas reagir e, em última instância, apresenta passividade.

O homem religioso não tem Amor fati - amor ao destino, ao que, segundo Nietzsche (2008b), é necessário; a fórmula para a grandeza no homem. Amor fati é um conceito de afirmação do destino e da vida.

Amor fati (amor ao destino): seja assim, de agora em diante, o meu amor. Não pretendo fazer a guerra ao que é feio. Não pretendo acusar, nem mesmo os acusadores. Desviarei o meu olhar, será essa, de agora em diante, a minha única negação! E, em uma palavra, portanto: não quero, a partir de hoje, ser outra coisa senão uma pessoa que diz Sim! (NIETZSCHE, 2003, p.143).

Sem vontade de potência e Amor fati, o homem religioso perdeu sua capacidade de criar e de vivenciar o presente. É ressentido. Busca pelo oculto, por sua remuneração divina, pelo que acredita que há por vir por seu sofrimento e humilhação, confortando-se em seu ressentimento. Concentra todas as suas forças no ressentir; na memória. Não consegue superar sua tristeza e abraçar o devir. "Vemos qual é o sintoma principal desse tipo: uma prodigiosa memória. Nietzsche insiste nessa incapacidade de esquecer qualquer coisa, nessa faculdade de nada esquecer, na natureza profundamente reativa dessa faculdade" (DELEUZE, 1976, p. 54).

Nietzsche apresenta a transvaloração dos valores - a abolição e superação de valores e a criação de novos - como solução para o problema moral. O filósofo defende que apenas espíritos-livres (os filósofos do futuro) podem provocar a transvaloração dos valores e assim construir a ponte para o super-homem (NIETZSCHE, 2011).

Todavia, para que seja possível criar novos valores - completando, assim, o processo de transvaloração -, é necessário que se transgrida e subverta valores já estabelecidos. "Do

\footnotetext{
7 "Desconfio de todas as pessoas com sistemas e as evito. A vontade de sistema constitui uma falta de lealdade" (NIETZSCHE, 2001, p. 10).
} 
legítimo pensador, exige-se que ele "crie valores". Mas, para tal tarefa, é preciso primeiro romper com os valores que nos construíram" (SCHÖPKE, 2004, p. 175). A análise fílmica de Tommy, com seus críticos, satíricos e transgressores discursos audiovisuais, desvela uma afiada crítica ao agenciamento religião.

\section{TOMMY: O FILME}

O filme Tommy - musical, de 1975, baseado no álbum/ópera rock homônimo, de 1969, da banda britânica The Who - é um dos trabalhos mais marcantes da carreira do controverso cineasta e roteirista britânico Ken Russell.

Papéis principais: Roger Daltrey (Tommy Walker), Ann-Margaret (Nora Walker, mãe de Tommy), Oliver Reed ("Uncle” Frank Hobbs, padrasto de Tommy). O filme ainda conta com ilustres atores e músicos em seu elenco, como Pete Townshend, Keith Moon, John Entwistle, Jack Nicholson, Elton John, Tina Turner, Eric Clapton entre outros. A atriz AnnMargaret ganhou o Globo de ouro e concorreu ao Oscar de melhor atriz por seu papel no filme. Pete Townshend também concorreu ao Oscar por adaptar a música de Tommy para o filme.

Segue uma breve descrição narrativa do filme.

"Tommy" conta a história de um garoto, Tommy Walker, que, após testemunhar a morte de seu pai (assassinado pelo então amante de sua mãe - seu futuro padrasto), entra em um estado de profundo autismo ${ }^{8}$, ficando cego, surdo e mudo. A partir de tal acontecimento, sua mãe e seu padrasto tentam curar o menino das mais variadas formas. Portanto, levam-no à igreja, às drogas e ao médico para tentar achar uma cura para Tommy. Esforços, estes, infrutíferos.

Guiado por si mesmo até uma máquina de Pinball, Tommy encontra aquilo que tanto necessitava: um caminho para a autossuperação. O garoto se consagra campeão no jogo e uma inspiração para os jovens; o declarado "Pinball Wizard". Mas Tommy ainda não está curado. Todavia, a cura não parte da religião, das drogas ou da medicina, mas do encontro de Tommy com ele mesmo - ilustrado pelo simbolismo da quebra de um espelho. A partir deste momento, Tommy se liberta de seu bloqueio; seu profundo autismo.

Tommy, não obstante, não quer apenas ser livre. Quer que todos o sejam. Logo, começa a pregar seu estilo de vida baseado em seu jogo de Pinball às pessoas. Rapidamente, ganha seguidores e se torna uma espécie de líder religioso; ídolo pop - o messias do Pinball.

\footnotetext{
8 "Chamamos Autismo ao desligamento da realidade combinado com a predominância relativa ou absoluta da vida interior” (BLEULER, 1911, apud DURVAL, 2011, p. 7).
}

Comun. \& Inf., Goiânia, GO, v. 19, n. 01, p. 105-122, jan./jun. 2016 
A mensagem de Tommy é institucionalizada, dogmatizada e até comercializada. Tommy é uma sensação.

Seu "rebanho", entretanto, se volta contra ele. Não aceita seus dogmas e seus caros instrumentos para iluminação. A liberdade de Tommy não alcança seus devotos. A crença no mago do Pinball é, enfim, extinta.

Com roteiro e narrativa pouco convencionais e uma riqueza imagética e sonora repleta de metáforas e simbolismos, o discurso de Tommy é passível de inúmeras interpretações e análises. Todavia, desenvolve-se uma análise fílmica que leva em conta o referencial teórico apresentado.

\section{TOMMY: A ANÁLISE}

Ao testemunhar a morte de seu pai, assassinado pelo amante de sua mãe (seu futuro padrasto), Tommy é enclausurado em ressentimento. O garoto bloqueia sua visão, fala e audição, apresentando um profundo estado de autismo. O ressentimento, aqui engendrado pelo trauma psíquico de Tommy $^{9}$, mais tarde, vai consubstanciara crítica à religião empreendida pelo discurso do filme.

Ilustra-se, na Figura 1, a imagem do trauma, na qual sua mãe e seu padrasto impõem a Tommy: "você não ouviu isso. Você não viu isso. Você nunca tinha ouvido isso. Nenhuma palavra disso. Você não vai dizer nada a ninguém, nunca dizer a uma alma o que você sabe que é a verdade ${ }^{10}$ ". Na Figura 2, o menino aparece com um cubo ou uma caixa metálica no lugar da cabeça, ilustrando seu enclausuramento psicológico, seu ressentimento, que o impede de experienciar o presente e de reagir diante do que aconteceu. A legenda, "a doença irá certamente se apossar da mente ${ }^{11}$ ", consubstancia a ideia de ressentimento que, para Nietzsche (apud PASCHOAL, 2008), é um problema fisiológico que acomete o indivíduo que não consegue superar os males da vida nem digerir sentimentos ruins, impedindo-o de viver efetivamente o presente. Logo, esse indivíduo não abraça seu destino, apenas ressente. Não possui Amor fati.

\footnotetext{
${ }^{9}$ O trauma de Tommy pode também ser considerado causa de histeria. Segundo Freud (1987, p. 43), "Nas neuroses traumáticas, a causa atuante da doença não é o dano físico insignificante, mas o afeto do susto - o trauma psíquico. De maneira análoga, nossas pesquisas revelam para muitos, se não para a maioria dos sintomas histéricos, causas desencadeadoras que só podem ser descritas como traumas psíquicos".

10 "You didn't hear it. You didn't see it. You never heard it. Not a word of it. You won't say nothing to no one, never tell a soul what you know is the truth".

11 "Sickness will surely take the mind".
}

Comun. \& Inf., Goiânia, GO, v. 19, n. 01, p. 105-122, jan./jun. 2016 
Figuras 1 e 2 - Imagens do filme Tommy

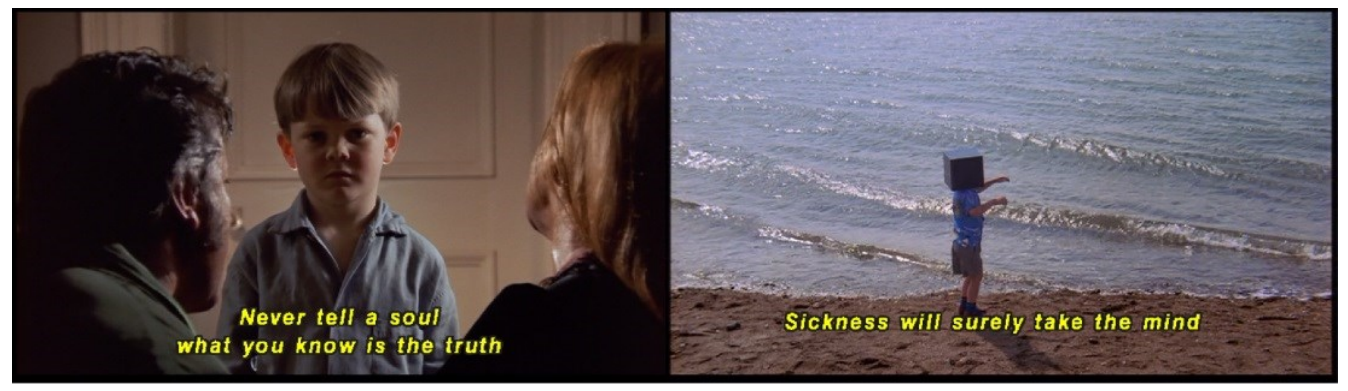

Fonte: Tommy (1975)

O Ressentimento impossibilita a Tommy a vontade de potência e o desejo ${ }^{12}$ - a experiência do devir, pois este, segundo Deleuze (apud ZOURABICHVILI, 2004, p. 24), “é o conteúdo do próprio desejo (máquinas desejantes ou agenciamentos): desejar é passar por devires". O ressentimento não permite que Tommy esqueça seu trauma, logo, seu devir é comprometido. "Grava-se algo a fogo, para que fique na memória: apenas o que não cessa de causar dor fica na memória" (NIETZSCHE, 2008a, p. 50).

Existe um fragmento do filme (ilustrado nas Figuras 3 e 4) em que Tommy, sua mãe, seu padrasto e várias outras personagens estão em uma sala decorada para uma festa natalina. Sua mãe está preocupada, porque "Tommy não sabe que dia é hoje. Ele não sabe quem foi Jesus ou o que é rezar ${ }^{13}$ ", então, "como ele pode ser salvo? [...] como pode um homem que nunca viu a luz ser iluminado? ${ }^{14 ”}$ A mãe de Tommy, então, coloca um boneco de presépio de Maria (mãe de Jesus) na mão do menino, mas Tommy leva sua mão (na qual está o boneco que representa Maria) contra o presépio destruindo-o.

Figuras 3 e 4 - Imagens do filme Tommy

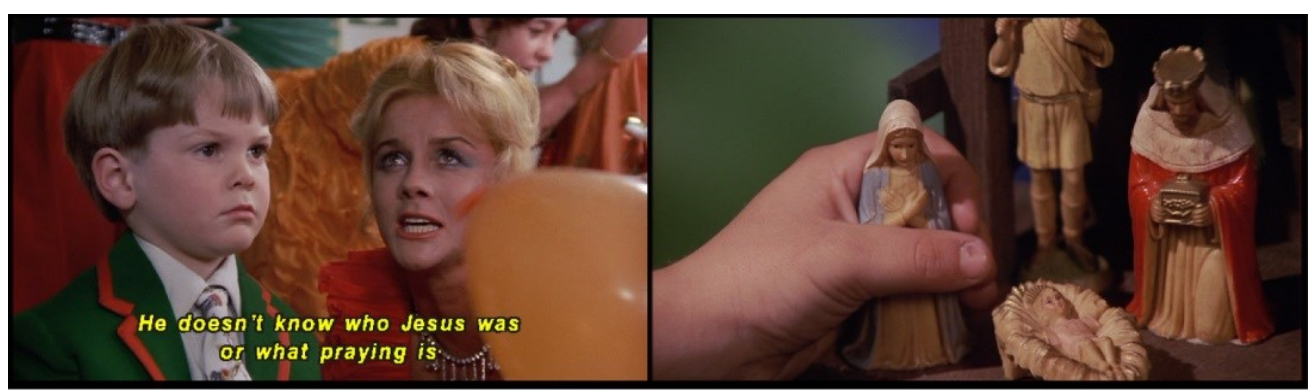

Fonte: Tommy (1975)

\footnotetext{
12 Retoma-se a interpretação de que Tommy também pode ser um histérico a partir de Lacan (1959 apud CASTRO, 2012, p. 3): "a histeria caracteriza-se pela fundação de um desejo enquanto insatisfeito".

13 “Tommy doesn't know what day it is. He doesn't know who Jesus was or what praying is".

14 "How can he be saved? [...] How can men who've never seen light be enlightened?"
}

Comun. \& Inf., Goiânia, GO, v. 19, n. 01, p. 105-122, jan./jun. 2016 
Tal fragmento é um bom exemplo de transgressão moral. Tommy não sabe quem é Jesus e isto, de fato, não tem importância para ele. Jesus não pode curá-lo, não pode acabar com seu sofrimento. Portanto, tal valor não devia ser imposto a ele. A ideia da destruição do presépio remete a uma transgressão moral. Um valor transgredido, pois se mostrou irrelevante.

Outro exemplo interessante se dá no fragmento de Sally Simpson, a menina que idolatra Tommy, mas que "sabia desde o começo, no fundo de seu coração, que ela e Tommy eram de mundos diferentes ${ }^{15}$ ". Seu pai, um pastor cristão, não a deixou ir ao evento em que Tommy falaria com seus discípulos. Sally, triste e enfurecida com a situação, joga o livro de seu pai no fogo (como ilustrado na Figura 5), ignora-o e vai ao evento. A transgressão se dá não só pelo livro jogado no fogo se chamar "Um soldado para Jesus", mas também por ser o livro de seu próprio pai e ela desobedecer a sua ordem para ver seu idolatrado messias. A moral (de seu pai) quer prender Sally aos valores cristãos e familiares, mas ela os transgride para buscar outros valores. Moral, para Foucault (1998, p. 24), é "um conjunto de valores e regras de ação propostas aos indivíduos e aos grupos por intermédio de aparelhos prescritivos diversos, como podem ser a família, as instituições educativas, as Igrejas, etc.”.

Figura 5 - Imagem do filme Tommy



Fonte: Tommy (1975)

Durante todo o filme, a figura da cruz se repete. Há um fragmento, por exemplo, em que o pai de Tommy, membro da aeronáutica durante a guerra, aparece crucificado na frente de um avião que imita uma cruz pela maneira que está posicionado à vista, como ilustrado na Figura 6. A imagem do pai crucificado se transforma em uma espécie de cruz cuja parte superior é uma bola de Pinball (Figura 7), que, posteriormente, é utilizada como símbolo da religião criada por Tommy.

\footnotetext{
15 "She knew from the start deep down in her heart that she and Tommy were worlds apart".
} 
Figuras 6 e 7 - Imagens do filme Tommy

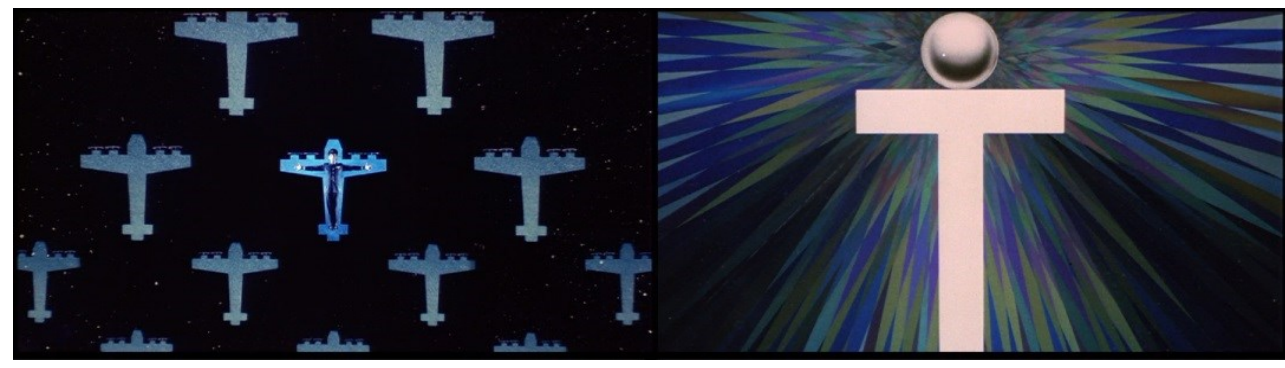

Fonte: Tommy (1975)

A ideia passada com a cruz é a de sátira. Tal recurso é reutilizado durante vários tempos do filme para aproximar religiões existentes das religiões criadas pelo filme. $\mathrm{O}$ discurso de Tommy toma o intertexto ${ }^{16}$ "sagrado" e "consagrado" de certas religiões para desenvolver uma crítica. Para Hodgart (1969), a sátira é um protesto contra as regras do jogo social, mas também contra aqueles que julgam.

Há uma cena em que Tommy e sua mãe vão a uma igreja pouco convencional. Ambos estão ali para assistir ao pastor (Eric Clapton) pregar a palavra de Marilyn Monroe. O pastor atribui a Marilyn as palavras "amar", "magia", "poder" e "curar" e exclama: "Ela traz vista aos cegos [...] os mudos começam a falar [...] e os surdos podem ouvir". Atributos, estes, frequentemente vinculados a grandes messias, líderes de religiões, deuses.

A ideia de sátira está presente neste excerto também, pois Marilyn é adorada como em religiões comuns no filme. Os devotos ritualizam sua adoração pela "deusa" Marilyn Monroe bebendo uísque e consumindo drogas, como ilustrado na Figura 8. Também beijam os pés de sua estátua (Figura 9) e passam a mão sobre seu vestido para transmitir sua energia poderosa, criadora e curativa a deficientes físicos.

Tal fragmento traz além de uma crítica à idolatria por celebridades (estrelas de cinema, da música, da TV, etc.), mas também uma crítica a qualquer adoração, pois o objeto de adoração toma ares de celebridade e vice versa. $\mathrm{O}$ símbolo conferido à religião de Marilyn é uma estrela, o que consubstancia a crítica ao culto a celebridades.

\footnotetext{
16 "Intertexto, por sua vez, é o texto específico (ou o corpus de textos específicos) com que um determinado texto mantém o intercâmbio semiótico que caracteriza a intertextualidade" (ALÓS, 2006, p. 14).
} 
Figuras 8 e 9 - Imagens do filme Tommy

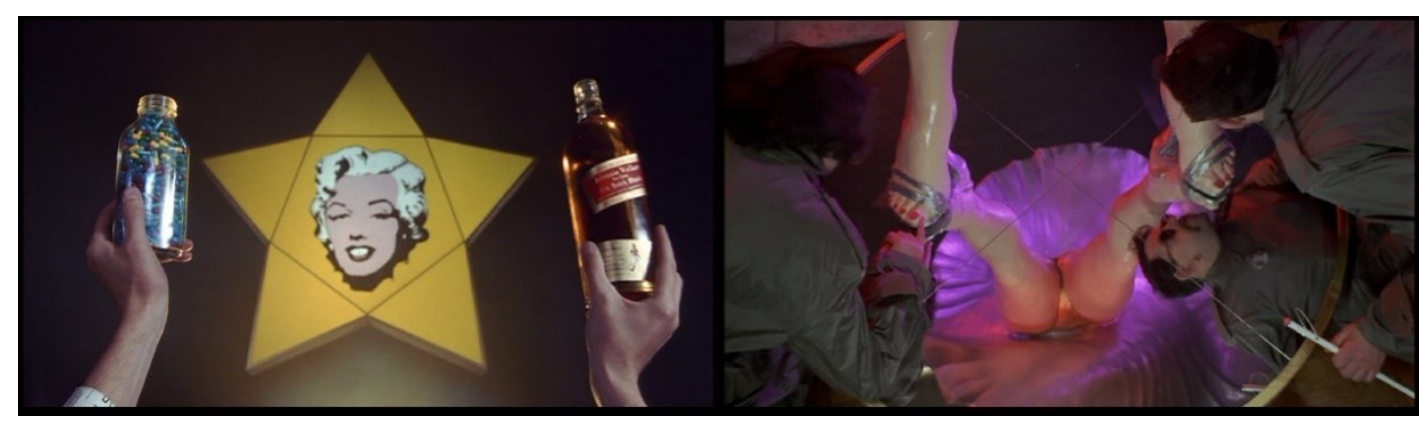

Fonte: Tommy (1975)

É evidente a aproximação discursiva (imagética e textual e, de certa forma, também narrativa) entre Tommy e Jesus no filme. Frequentemente sua figura remete a poses e vestimentas famosas do carismático messias. Tal aproximação confere a esses discursos a ideia de sátira também.

Há um fragmento do filme em que o garoto é levado por seu padrasto a uma cigana, a rainha do ácido (Tina Turner). Tommy experiencia uma viagem lisérgica (o filme também deixa aberta a interpretação de uma possível relação sexual entre a cigana e Tommy, pois ambos vão para um quarto de prostíbulo) e sua imagem vai se transformando no decorrer da viagem. Uma das imagens ilustradas é a de Tommy vestindo um tecido branco na virilha muito similar às vestimentas de Jesus nas imagens de sua crucificação. Tal comparação pode ser feita a partir das Figuras 10 e 11.

Figuras 10 e 11 - Imagens comparativas: Tommy e Jesus

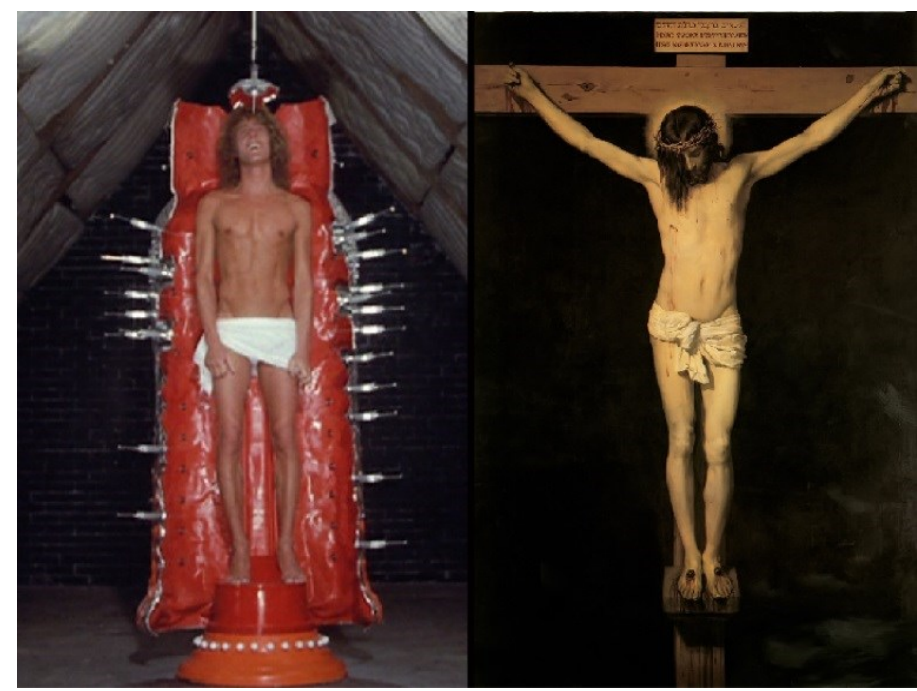

Fontes: Imagem à esquerda - Tommy (1975). Imagem à direita. Disponível:< http://www.trinitychurchashland.org/wp-

content/uploads/2013/03/christ_on_the_cross_diego_velazquez_1632.jpg >. Acesso em: fev. 2016

Comun. \& Inf., Goiânia, GO, v. 19, n. 01, p. 105-122, jan./jun. 2016 
Outra imagem interessante desse fragmento é a de Tommy usando uma coroa de flores, uma cruz em seu pescoço, várias flores pregadas por todo seu corpo e segurando bolas prateadas. Quando o foco está em seu rosto, a semelhança entre Tommy e Jesus é gritante, como pode ser evidenciado comparando as Figuras 12 e 13. Ambos têm cabelos compridos, coroas (a de Jesus de espinhos, a de Tommy de flores) e sangue escorrendo por suas faces.

Figuras 12 e 13 - Imagens comparativas: Tommy e Jesus

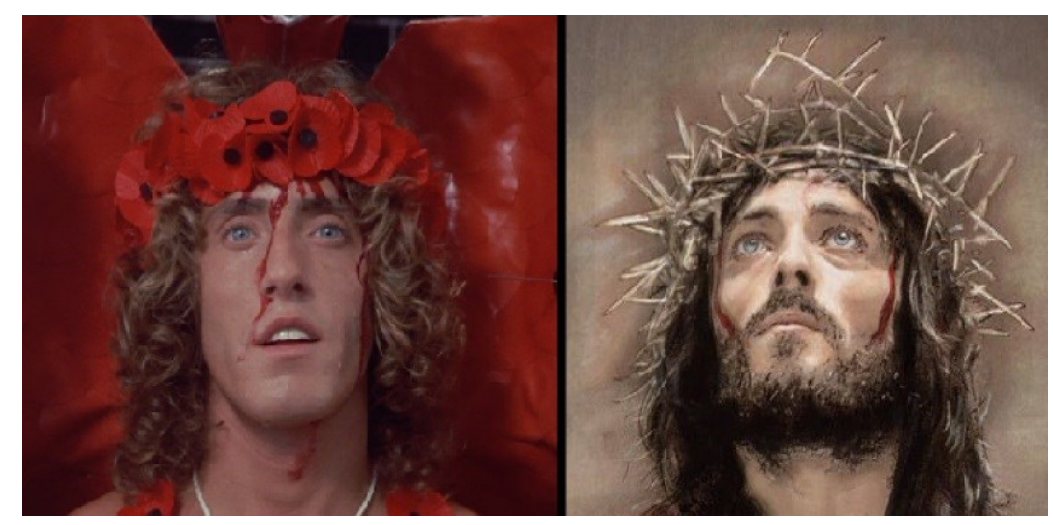

Fontes: Imagem à esquerda - Tommy (1975). Imagem à direita - Disponível em:<https://br.pinterest.com/pin/466333736392611579/>. Acesso em: fev. 2016

Há outros excertos interessantes que relacionam a imagem de Tommy com a de Jesus. Tommy, já curado, enquanto canta "I'm a Sensation" (Eu sou a sensação), brada para a multidão que está a ouvi-lo: "Eu sou a luz". Tal afirmação remete a declaração de Jesus na Bíblia "Eu sou a luz do mundo; quem me segue de modo algum andará em trevas, mas terá a luz da vida" (JOÃO, 8:12). Tommy, na referida canção, diz que é uma nova vibração. No entanto, não só sua imagem se mostra semelhante à de Jesus, mas também seu texto. Nada em Tommy, enquanto messias é, de fato, novo, mas ele é indubitavelmente popular e carismático. A ideia de que Tommy é uma "sensação" remete não só a uma percepção, mas também a uma admiração, um encantamento.

Tommy chama seus discípulos para a sua casa. Diz a eles que vão beber a noite toda e nunca dormir. Tommy aparece em poses messiânicas - de pernas cruzadas ou com os braços estendidos para os espectadores. Esta última remete a uma pose bastante emblemática de Jesus, como pode ser evidenciado na comparação entre as Figuras 14 e 15. Tommy, assim como Jesus o fez, convida as pessoas a seguirem-no. 


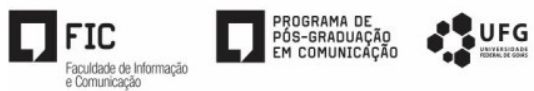

Figuras 14 e 15 - Imagens comparativas: Tommy e Jesus

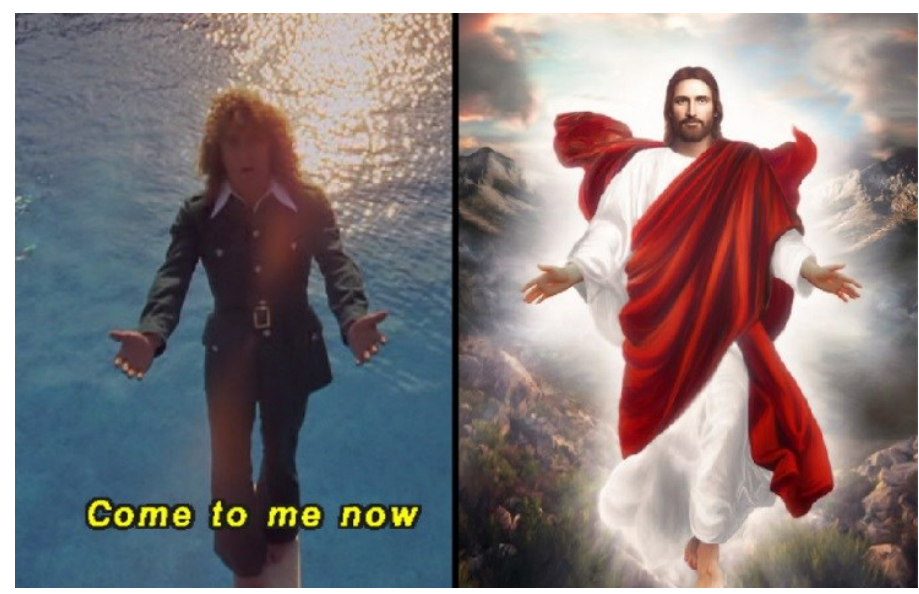

Fontes: Imagem à esquerda - Tommy (1975); Imagem à direita - Disponível em: $<$ https://br.pinterest.com/pin/557250153868152209/>. Acesso em: fev. 2016

Na casa de Tommy, o messias se senta a mesa no centro e seus seguidores ao lado dele (Figura 16). Uma mesa estreita e comprida. Mais uma imagem que remete a outra imagem emblemática de Jesus - sentado no centro da mesa acompanhado de seus discípulos A Última Ceia, de Leonardo da Vinci (Figura 17).

Figuras 16 e 17 - Imagens comparativas: Tommy e Jesus

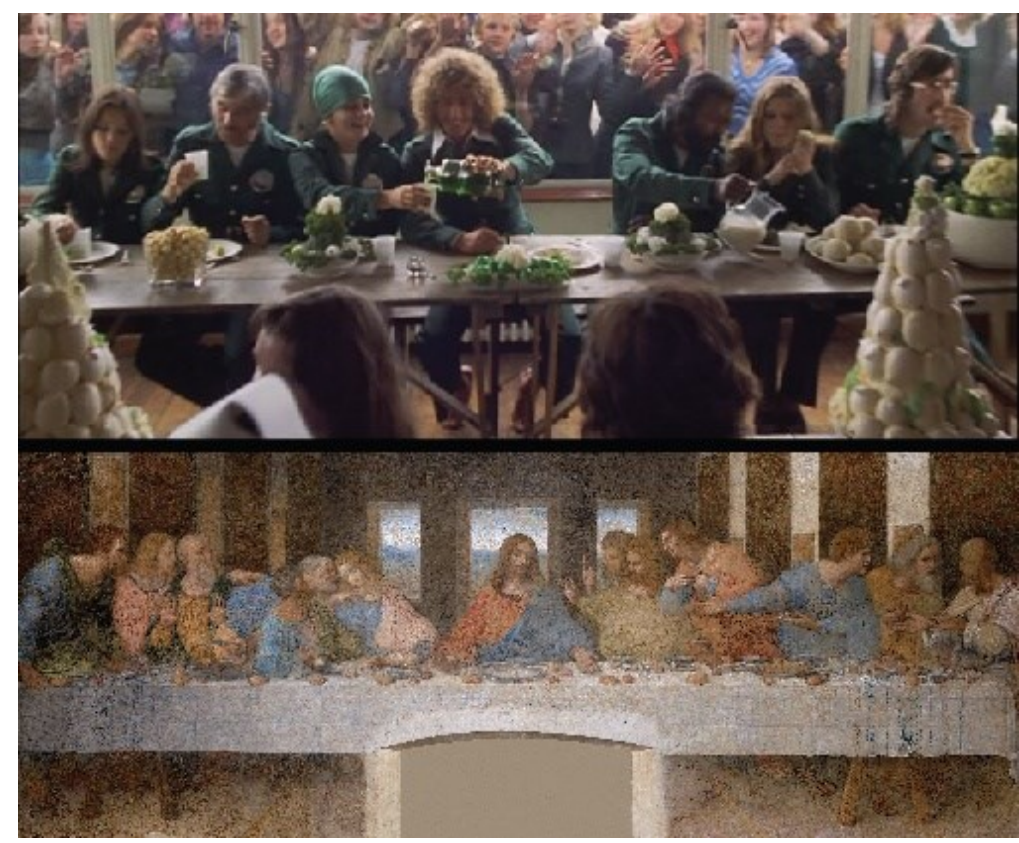

Fontes: Imagem de cima - Tommy (1975). Imagem de baixo - Wikipédia

Segundo Bosi (1977, p. 162), “o lugar de onde se move a sátira é, claramente, um topos negativo: a recusa aos costumes, à linguagem e aos modos de pensar correntes". Logo, a 


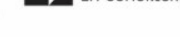

sátira é, também, discurso transgressor; serve não apenas para a crítica, mas para promover a dessacralização de certas imagens e possibilitar novas imagens e valores.

Tommy está curado. Sua necessidade máxima, a qual clama durante todo o filme "Veja-me. Sinta-me. Toque-me. Cure-me ${ }^{17 " ~-~ f o i ~ a t e n d i d a . ~ D e ~ a c o r d o ~ c o m ~ F o u c a u l t ~(2000), ~ o ~}$ homem pensa primeiramente em suas necessidades, depois em seus prazeres. "Quando se volta sobre si mesmo e começa a refletir, prescreve regras para seu juízo, é a lógica, para seus discursos, é a gramática, para seus desejos, é a moral" (FOUCAULT, 2000, p. 103).

Tommy criou uma religião (uma moral) que, para ele, faz todo o sentido e conquistou multidões de devotos. Porém, seus valores não se aplicam a todos. Seus caros instrumentos para a iluminação são ineficazes. Sua liberdade não os alcança. Seus fiéis perguntam-no: "como podem todas estas trivialidades nos levar ao objetivo que você alcançou? ${ }^{18 " . ~ A ~ m o r a l ~ d e ~ T o m m y ~ s o ́ ~ f u n c i o n a ~ p a r a ~ e l e ~ m e s m o ~(c o m ~ s e u s ~ p r o ́ p r i o s ~ d e s e j o s) ~ e ~}$ não pode ser transmitida para seus seguidores.

Entretanto, Tommy é dogmático. Exclama: "se você quer me seguir, você tem que jogar Pinball. E colocar seus tampões de ouvido. E colocar seus óculos. Você sabe onde colocar a rolha ${ }^{19}$ ". Tais instrumentos remetem a ideia de alienação, assim como de castração. Os devotos do messias do Pinball não podem ouvir, ver ou falar (como ilustrado na Figura 18). Não podem sequer pensar por si próprios. A religião deforma os sentidos e condena os instintos.

Figura 18 - Imagem do filme Tommy

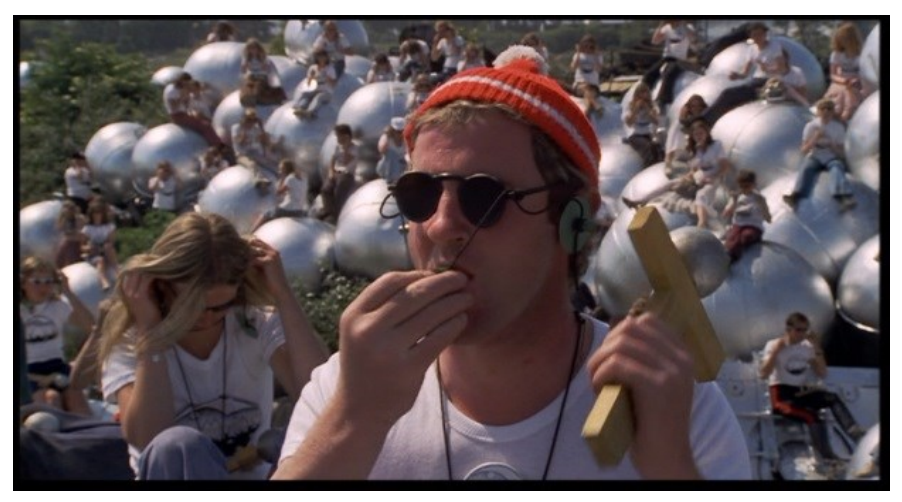

Fonte: Tommy (1975)

Tommy também não admite vícios ou luxos. É inflexível em seu discurso. Quem quer segui-lo e ter a liberdade que ele alcançou deve fazer o que ele diz. "A fórmula geral que

\footnotetext{
17 "See me. Feel me. Touch Me. Heal me".

18 "How can all this trivia take us to the goal you reached?"

19 "If you want to follow me, You've got to play Pinball. And put in your ear plugs

Put on your eye shades. You know where to put the cork".
}

Comun. \& Inf., Goiânia, GO, v. 19, n. 01, p. 105-122, jan.jun. 2016 
serve de base a toda religião e a toda moral pode ser expressada assim: 'Faça isto, e mais isto, não faça aquilo e mais aquilo - e então serás feliz, do contrário..." (NIETZSCHE, 2001, p. 35). A palavra de Tommy é lei. De acordo com Nietzsche (2008a), a moral, quando se sente forte o bastante, institui a lei, o que é permitido e proibido, o que é justo e injusto. Seus seguidores devem respeitar a lei imposta pelo messias. Suas vontades devem ser castradas. O santo é o perfeito castrado.

Enclausurados em ressentimento, os devotos do mago do pinball já não podem exercer poder criador; vontade de potência. Não podem experienciar efetivamente o presente. Não podem abraçar seus respectivos destinos e vidas (Amor fati). O mesmo bloqueio provocado em Tommy por sua mãe e seu padrasto acaba sendo produzido, dogmatizado e comercializado. Sua religião, portanto, enclausura seus devotos em um profundo autismo e, ao invés de liberdade e iluminação, seus discípulos encontram exploração e ressentimento.

Logo, seus fiéis se rebelam contra Tommy. No final do filme, a casa do messias é destruída e posta em chamas por seus discípulos. Tal fragmento dialoga com a destruição do presépio pelo garoto no começo do filme e com o ato de Sally Simpson de jogar o livro de seu pai no fogo e ir ver Tommy. Deste modo, a crença no Mago do Pinball foi transgredida e subvertida. A transgressão moral realizada possibilita ao homem exercer seu poder criador sua vontade de potência - livremente; alçar devires; desejar.

\section{CONSIDERAÇÕES FINAIS}

A análise fílmica de Tommy possibilitou uma compreensão maior do problema moral discutido no filme. Seus imorais, satíricos e transgressores fragmentos fílmicos são bons exemplos críticos que engendram novas discussões acerca do referido problema.

Foi possível evidenciar que o discurso que rompe com a moral possibilita a superação da mesma. A transgressão e superação de velhos e "supremos" valores torna possível a criação de novos a transvaloração de valores.

A idolatria e veneração que as religiões e o culto a celebridades promovem também não são poupadas pelo discurso de Tommy. A exemplo do fragmento sobre a religião de Marilyn Monroe e a própria história de Tommy enquanto messias. Homens são adorados como deuses por seus seguidores, logo, exercem grande poder sobre eles. Aqueles que detêm o poder criam modelos que os cabem para que os outros também sigam.

O agenciamento religião - dogmático, alienador, castrador dos sentidos e instintos, elenca no ressentimento o conforto de sua experiência, impedindo o exercício da vontade de 
potência e o Amor fati. Tommy perde seus sentidos diante de um trauma; ressentimento. Quando é, enfim, curado, tenta reproduzir seu bloqueio em seus seguidores. Logo, a religião cria uma estrutura autista em seus crentes, pois, enquanto agenciamento moral, não há moral fora dela; fora dela é fora da lei.

Entretanto, seus seguidores se voltam contra Tommy, pois o que o messias propõe não faz efeito nem qualquer sentido para eles. A liberdade de Tommy não alcança seus seguidores. $\mathrm{O}$ agenciamento religião, diferente da publicidade que faz de si mesmo, não possibilita a libertação, muito pelo contrário: prende seus seguidores a um modelo moral.

O discurso de Tommy é extremamente atual, pois visa quebrar paradigmas e modelos que ainda não foram completamente superados. Deseja-se que o discurso do filme Tommy permaneça incitando a quebra desses paradigmas e modelos morais; que sua crítica à religião gere novos debates e novas críticas; que o valor dos valores morais vigentes seja discutido mais amplamente; que o devir seja alçado; que velhos valores sejam superados; que novos valores sejam criados.

\section{REFERÊNCIAS}

ALÓS, A. P. Texto literário, texto cultural, intertextualidade. Revista Virtual de Estudos da Linguagem - ReVEL., São Paulo, v. 4, n. 6, p. 1-25, mar. de 2006.

AUMONT, J.; MARIE, M. A Análise do Filme. Lisboa: Armand Colin, 2013.

BIBLÍA. N. T. João. Português. Santa Bíblia. Tradução de João Ferreira de Almeida. [S.1, s.n.], 2006. Publicação eletrônica. cap. 8, vers. 12. Disponível em:

$<$ http://www.ebooksbrasil.org/adobeebook/biblia.pdf $>$. Acesso em: 15 jul. de 2015.

BOSI, A. O ser e o tempo da poesia. São Paulo: Cultrix, 1977.

CASTRO, J. C. Sujeito, Desejo e Identidade no discurso da histeria. In: SIMPÓSIO NACIONAL DISCURSO, IDENTIDADE E SOCIEDADE (SIDIS), 3., 2012, Campinas. Anais... Campinas: 2012.

DELEUZE, G. Nietzsche e a Filosofia. Rio de Janeiro: Editora Rio, 1976.

DELEUZE, G.; PARNET, C. Diálogos. Valencia: PRÉ-TEXTOS, 1980.

DURVAL, R. As esquizofrenias segundo Eugen Bleuler e algumas concepções do século XXI. Revista RevPsiq., São Paulo, v. 25, 2011. Número Especial.

FOUCAULT, M. As palavras e as coisas. 8. ed. São Paulo: Martins Fontes, 2000.

FOUCAULT, M. História da Sexualidade II: o uso dos prazeres. 8. ed. Rio de Janeiro: Graal, 1998. FREUD, S. Sobre o mecanismo psíquico dos fenômenos histéricos: comunicação preliminar (Breuer e Freud). Rio de Janeiro: Imago, 1987. v. 2, p. 41-53. Edição Standard Brasileira das Obras Psicológicas Completas de Sigmund Freud. 
HODGART, M. La sátira. Madrid: Guadarrama, 1969.

NIETZSCHE, F. A gaia ciência. São Paulo: Martin Claret, 2003.

NIETZSCHE, F. Assim falava Zaratustra. Rio de Janeiro: Nova Fronteira, 2012a.

NIETZSCHE, F. Ecce homo: Como alguém se torna o que é. São Paulo: Companhia das Letras, 2008 b.

NIETZSCHE, F. Genealogia da moral: uma polêmica. São Paulo: Companhia das Letras, 2008a.

NIETZSCHE, F. O crepúsculo dos ídolos ou a filosofia a golpes de martelo. Curitiba: Hemus, 2001.

NIETZSCHE, F. Para além do bem e do mal. São Paulo: Martin Claret, 2011.

NIETZSCHE, F. Vontade de Potência: ensaio de uma transmutação de todos os valores. 2012b.

PASCHOAL, A. As formas do ressentimento na filosofia de Nietzsche. PHILÓSOPHOS: Goiânia, v. 13, n. 1, p. 11-33, jan./jun. 2008.

PERNIOLA, M. Contra a comunicação. Lisboa: Editorial Teorema, 2005.

SCHÖPKE, R. Por uma filosofia da diferença: Gilles Deleuze, o pensador nômade. Rio de Janeiro: Contraponto / São Paulo: Edusp, 2004.

THE story of the who. The who, hists 50!, Estados Unidos, [s.d.]. Disponível em: $<$ http://thewho.com/history/>. Acesso em: 13 jul. 2015.

TOMMY. Direção: Ken Russell. LW Editora. Reino Unido, 1975, 111 min: son., color.

ZOURABICHVILI, F. O vocabulário de Deleuze. Rio de Janeiro: Centro Interdisciplinar de Estudo em Novas Tecnologias e Informação, 2004.

Recebido em: 31/07/2015

Aceito em: 11/09/2015

Publicado em: 11/10/2016 